\title{
Dynamic Interaction between Toc159 and Blue Light Receptors at the Chloroplast Outer Envelope of Pisum sativum (L.)
}

\author{
Heba Hamdy and Mohamed Ibrahim ${ }^{\#}$
}

Botany Department, Faculty of Science, Ain Shams University, Cairo, Egypt.

\begin{abstract}
$\mathbf{P}$ HYSIOLOGICAL significance of Pisum sativum TOC GTPases protein phosphoryation has linked the regulation of protein import into chloroplast with the environmental changes. Phototropin 2 is localized at outer membrane of chloroplast. It was crucial to study the relation between Phot2 localization at chloroplast membrane and phosphorylation of TOC GTPases under blue light intensities. Kinase activity of Phot 2 towards TOC GTPases was characterized in outer membrane of Pisum sativum. TOC GTPases were specifically and differentially phosphorylated under diffrent light quality and intensities. Gene chip analysis was performed to correlate between expression of TOC complex subunits and blue light receptors genes using $A$. thaliana. It was found that transcript level of $A t$ Toc 33 was the highest observed expression with At Toc159 and AtToc75-III. Also, 26 phototropins and photropin-like genes were identified. Coexpression gene netweork of AtPhot 2 has revealed a close connection with TPR-containing protein (At1g01320) and chloroplast Toc159 (AT4G15810). Co-immunoprecipitaion assay has evidenced that no intercation was detected between AtPhot2-KD and PsToc34. However, $A t$ Phot2-KD was found to interact with $A t$ Toc159. Chloroplast outer and inner envelopes purified from A. thaliana knockout line of Phot 2 has phosphorylated AtToc33 and AtToc86/159 in vitro. Hereby, Phot2 is not the specific protein kinase for TOC GTPases. Hence, it was suggested that certain signal cascades may directly or indirectly link phosphorylation of TOC GTPases, protein levels of PHOT-LIKE proteins and irradiation conditions. Therefore, TOC GTPases phosphorylation might be an external regulatory signal to regulate preproteins import into chloroplasts in response to light changes or as a signal of chloroplast biogenesis.
\end{abstract}

Keywords: Pisum sativum L., TOC complex, Toc159 receptor protein, Protein phosphorylation, Phototropin2.

\section{Introduction}

Light is one of the most essential environmental signals for plants. To sense and respond to the variable environmental light conditions, plants have developed two main light sensing systems: Phytochrome (Franklin \& Quail, 2010) and two blue light receptors; cryptochrome (Liu et al., 2011) and phototropins (Christie, 2007). Phototropins are plasma membrane light-activated serine/threonine protein kinases (Christie et al., 1998). Light sensing by the phototropins is mediated by a repeated motif at the N-terminal region of the protein known as the LOV domain. This domain contains two light-, oxygen-, or voltage-sensing (LOV) domains that bind oxidized flavin mononucleotide (FMN) as a UV blue light-absorbing cofactor (Christie et al., 1999). LOV domain photoexcitation results in autophosphorylation of light receptors and the initiation of phototropin signaling (Swartz et al., 2001; Kennis et al., 2003; Möglich et al., 2010 and Christie et al., 2012). The majority of plants, including Arabidopsis thaliana, have two phototropin homologues named Phot1 and Phot2, which share physiological responses depending on the intensity of light; these include phototropism, leaf positioning and expansion, chloroplast relocation movement, and stomatal opening (Sakai et al., 2001). Recent studies have evidenced that Phot 1 and Phot 2 signals are most likely elicited from the plasma membrane (PM) to the final destination by vesicular transport (Aggarwal et al., 2014) and trafficking mediated by the Golgi apparatus to the chloroplast surface (Kong et al., 2012). Moreover, Phot2 was found

"Corresponding author emails: mohamed.ibrahim591978@gmail.com, Mohamed_shehata@sci.asu.edu.eg Tel: 01201999270

DOI: 10.21608/ejbo.2018.5958.1239

Edited by: Prof. Dr. Wedad Kasim, Faculty of Science, Tanta University, Tanta, Egypt.

C2019 National Information and Documentation Center (NIDOC) 
and detected as chloroplast outer envelope protein after the core proteome of chloroplast envelope membranes was defined (Ibrahim, 2012 and Simm et al., 2013). Furthermore, Also, endogenous AtPhot2 was upregulated and heavily detected in the ppi1::S181A plant line (knouckout cell line of $A$. thaliana where serine to alanine exchange was performed to abolish the phosphorylation of AtToc33) (Oreb et al., 2007, 2008).

Translocation of chloroplast preproteins across its outer and inner membranes occurs through different paths, one of which is the coordination between the TOC (Translocon at outer envelope membrane of chloroplast) and TIC (Translocon at inner envelope membrane of chloroplasts) complexes (Becker et al., 2004; Soll \& Schleiff, 2004; Li et al., 2007 and Jarvis, 2008). TOC complex performs the initial recognition of the preproteins and their translocation across the outer membrane (Schnell et al., 1997). Then, TIC complex physically associates with the TOC complex subunits and dispenses the membrane translocation channel for the inner membrane. TOC core complex that was found to be functionally active and sufficient for in vitro transport of a preproteins in lipid vesicles consists of two GTPases receptor proteins; Toc34 \&Toc159 and one channel protein, Toc75 (Schleiff et al., 2003). The transfer of the precursor imported protein (immature cytosolic form) toward the TOC translocon is regulated by a series of cTP (recognizable chloroplast cleavable transit peptide guiding the protein to and into the chloroplast) phosphorylation/dephosphorylation (Waegemann \& Soll, 1996; Sveshnikova et al., 2000 and Martin et al., 2006). The TOC complex receptor protein Toc34 (Kessler et al., 1994), a membrane anchored GTP-binding protein, can recognize the phosphorylated cTP (Schleiff et al., 2002) and precursor protein guiding 143-3 proteins (Qbadou et al., 2006) in a GTPdependant manner. Following release of the associated guiding complex, the precursor is transferred to Toc34 (Qbadou et al., 2006). By means of GTP hydrolysis and GDP release from Toc34, the precursor is then transferred to Toc159 (Schleiff et al., 2003). TOC GTPase receptor protein regarded as a driver motor of the translocation process and subsequently pushed through the pore-forming Toc75, TOC complex $\beta$-barrel shaped channel (Hinnah et al., 2002).
Protein targeting toward and translocation into chloroplasts is a highly ordered process involving the action of protein kinases and phosphatases as well as a GTP dependent TOC machine at the chloroplast membrane (Fulgosi \& Soll, 2002 and Jelic et al., 2002, 2003). Toc34 and Toc159 are phosphorylated at their $\mathrm{G}$ domains by distinct protein kinases present in the hosting chloroplast outer membrane (Fulgosi $\&$ Soll, 2002). The phosphorylation of Toc34 inhibits the recognition of precursor proteins and GTP binding. Disruption of Toc34 association from the TOC core complex was observed (Oreb et al., 2008). Hence, phosphorylation of Toc34 serves as an inhibitor for its assembly with other components of the TOC core complex. Hereby, phosphorylation and GTP hydrolysis tightly regulate this molecular ensemble (Oreb et al., 2008 and Agne \& Kessler, 2009). Interestingly, in A. thaliana three isofrms of Toc159 were identified, namely At Toc132, AtToc120, and At Toc90 (Kubis et al., 2004) and two isoforms of the Toc34 GTPase were identified, namely AtToc34 and atToc33 (Vojta et al., 2004). Functional distinction between the two receptors was investigated (Jelic et al., 2003 and Vojta et al., 2004). It has been reported that At Toc33 is utilized for translocation of photosynthetic proteins and At Toc34 for the import of housekeeping proteins (Vojta et al., 2004). Comparing psToc34 from $P$. sativum with $A t \operatorname{Toc} 34$ and $A t$ Toc33 from $A$. thaliana has revealed that only one isoform, namely AtToc33 is phosphorylated (Jelic et al., 2003). Although the phosphorylation of Toc34 is already known for several years, several questions regarding the phosphorylation status of the two Toc34 isoforms from A. thaliana, the molecular components involved in the regulation of the phosphorylation process, precisely what is the protein kinase and where this kinase is initially localized, so far remained unclear. In vivo, complemented AtToc33 knockout line (ppi1), plastid protein import mutant, with the phosphomimicking mutation has shown a reduction in the photosynthetic performance as well as chloroplast biogenesis in the transgenic lines at an early developmental stage (Oreb et al., 2007). However, the identification of the physiological relevance of TOC GTPases phosphorylation is not accomplished in details so far (Oreb et al., 2008 and Agne \& Kessler, 2009).

This study aims for comprehensive understanding of the overlapping of phot2 
localization at the outer envelope of chloroplast with the phosphorylation of TOC GTPases. This may expand our understanding regarding timing, physiological relevance, and regulatory mechanism by which protein import into chloroplast is regulated. Also, the nature of the interaction between Phot 2 and chloroplast outer membrane protein(s) was focused. To answer the questions to this subject, biochemical, biophysical and molecular techniques will be performed.

\section{Materials and Methods}

\section{Materials}

Pisum sativum L. (Garden pea) seeds, cultivar Master B, were kindly provided by Crop Research Center, Agricultural Research Center (ARC), Giza, Egypt. Seeds of Arabidopsis thaliana L. (thale cress) wild type (WT) and knockout (KO) individual mutants of Phot1 ( $\triangle$ AtPhot1) and Phot2 ( $\triangle A t$ Phot2) were kindly provided by Prof. Dr. John Cristie, Professor of photobiology, Institute of Molecular Cell and Systems Biology, Scotland. Mouse monoclonal anti-Phosphoserine (Anti-PhosSer) antibody was obtained from Invitrogen (Camarillo, CA). Antisera against GTPase domains (G-domain) of PsTOC159 and PsTOC34 were kindly lyophilized and provided by Prof. Dr. Enrico Schleiff (Head of the Institute for Molecular Cell Biology of Plants, Molecular Biosciences Department, JWG University, Frankfurt, Germany). The antibody raised against kinase domain of AtPhot2 (AtPHOT2-KD) was kindly provided by Prof. Dr. John Cristie. For immunoprecipitation experiments, the beads of Protein-A-Sepharose were obtained from GE Healthcare (Freiburg, Germany). The rest of used chemicals, reagents, and kits throughout this study were purchased from Promega (Madison, USA).

\section{Methods}

Purification of chloroplasts and chloroplasts envelopes from P. sativum L. and A. thaliana $L$.

Pure intact chloroplasts were isolated from garden pea (Pisum sativum L.) of seven days old plants grown in long day $\left(16 \mathrm{~h}\right.$ light, $21^{\circ} \mathrm{C} /$ $8 \mathrm{~h}$ dark, $16^{\circ} \mathrm{C}$ ) newly established greenhouse chambers facility of Botany Department, Faculty of Science, Ain Shams University. The isolation and purification procedure depended on Percoll ${ }^{\mathrm{TM}}$-based gradient centrifugation using 40$80 \%(\mathrm{v} / \mathrm{v})$ percoll $^{\mathrm{TM}}$. The purification procedure was performed as described previously (Schleiff et al., 2003; Ibrahim, 2012 and Salah et al., 2016). Outer envelope membrane proteins (OEPs) were purified from intact osmotically-shocked and mechanically-disrupted chloroplasts. Purification of chloroplast membrane proteins was performed using sucrose density gradient centrifugation. Constructed sucrose gradients and fractionation of chloroplast membranes via differential ultracentrifugation were carried out as previously described by Simm et al. (2013). Intact chloroplasts of $A$. thaliana were isolated from twenty-day-old plants. Percoll ${ }^{\mathrm{TM}}$ gradients were constructed by $45-85 \% \quad(\mathrm{v} / \mathrm{v})$ percoll ${ }^{\mathrm{TM}}$. The purification procedure was followed as investigated previously by Simm et al. (2013). Recovered chloroplasts were washed, centrifuged, resuspended in TE buffer, and stored in $-80^{\circ} \mathrm{C}$ until further applications. Mixed chloroplast envelopes were isolated by sucrose density gradient centrifugation using osmotically-shocked and mechanically-disrupted chloroplasts. Intact layer of fractionated mixed envelopes was retrieved by glass Pasteur pipette, washed, centrifuged, resuspended in TE buffer, and stored in $-80^{\circ} \mathrm{C}$ until further use (Ibrahim, 2012 and Simm et al., 2013).

\section{Blue light (BL) treatments}

Under long day conditions (16h light, $21^{\circ} \mathrm{C} /$ $8 \mathrm{~h}$ dark, $16^{\circ} \mathrm{C}$ ) at normal light photoperiod, seedlings of $A$. thaliana and $P$. sativum were grown for twenty and seven days, respectively, for chloroplasts and/or OEPs isolation. Pea seedlings were grown on MS medium (Sambrook et al., 1989) with minor modifications as demonstrated previously by Salah et al. (2016). Pea plants were pre-illuminated by BL spectrum (at $15 \mathrm{~cm}$ apart from plant seedlings at Botany Department imaging dark room) using BL filter under low $\left(5,10\right.$, and $\left.20 \mu \mathrm{mol} \mathrm{m} \mathrm{m}^{-2} \mathrm{~s}^{-1}\right)$ and high $(30,50$, and $70 \mu \mathrm{mol} \mathrm{m} \mathrm{m}^{-2} \mathrm{~s}^{-1}$ ) photon flux intensity for one hour prior to chloroplast and/or OEPs isolation for in vitro protein phosphorylation assay.

Gene chip analysis and construction of coexpression gene network

The expression level of TOC complex and phototropins related genes were analyzed. Light treatment for one hour was performed as described by Schleiff et al. (2003). Subsequently, gene chip analysis of Affymetrix ATH1 Arabidopsis Genome Array (Affymetrix, High Wycombe, United Kingdom) was carried out using extracted RNA from twenty-day-old wild 
type $A$. thaliana according to Vojta et al. (2004). The data of gene transcripts were analyzed using the provided software by Affymetrix (MAS). Co-expressed gene network, using AtPHOT2 gene ID at TAIR database, was constructed by online module ATTED-II ver.9.2 (Obayashi et al., 2018) co-expression platform of $A$. thaliana to find out and assess the possible co-regulated and interacting partners between phototropins and OEPs of chloroplast.

In vitro protein phosphorylation assay (protein kinase assay)

Intact purified chloroplasts or chloroplast OEPs harboring the potential protein kinase activity were incubated for $20 \mathrm{~min}$ at room temperature in $20 \mathrm{mM}$ Tris- $\mathrm{HCl}, \mathrm{pH}$ 7.6, containing $5 \mu \mathrm{M}$ ATP, $5 \mathrm{mM} \mathrm{MgCl}_{2}$, and $0.2 \mathrm{mM}$ Na-orthovanadate. Then, phosphorylation reaction was terminated by adding 4x SDS sample buffer. The samples were fractionated on $12 \%$ SDS-PAGE. Phosphoserine-containing polypeptides, showing the incorporation of $\gamma$-phosphate into proteins, were identified by western blot technique against Anti-PhosSer antibody.

\section{Protein electrophoresis and primary interaction immunoassays}

Protein electrophoretic separation on $12 \%$ SDS-PAGE was either followed by gel staining with Coomassie blue R-250 (Laemmli, 1970) or blotting onto a nitrocellulose membrane $(0.1 \mu$, Schleicher \& Schull, Germany) in Towbin-buffer (192mM Glycine, 25mM Tris/HCl, pH 8.3, 0,1\% (w/v) SDS, and 15\% (v/v) Methanol) using wet transfer system (Scie-Plas, Cat. number TV100EBK) according to manufacturer's instructions. Phosphate buffered saline (PBS) supplemented with Tween-20 was used for membranes washing steps intervening the primary and secondary antibodies incubation times. Monoclonal primary antibodies against PsTOC159 and PsTOC34 G-domains, phosphorylated serine residue, and alkaline phosphatase-conjugated secondary antirabbit IgG (Agrisera) were used. Immunoblotting (western blotting, WB) technique was carried out as described previously by Kausch \& Handa (1997). Co-immunoprecipitaion (Co-IP) protocol of $1.5 \%(\mathrm{w} / \mathrm{v})$ digitonin-solubilized chloroplast OEPs using $\alpha$-AtPHOT2-KD was performed using IP-buffer containing $25 \mathrm{mM} \mathrm{HEPES} / \mathrm{KOH}$, $\mathrm{pH} 7.6,150 \mathrm{mM} \mathrm{NaCl}$ as previously described by Sambrook et al. (1989).

\section{Results and Discussion}

Blue light dependent phosphorylation of OEPs of chloroplasts

To investigate the effect of light quality and intensity on the phosphorylation level of chloroplast OEPs and trace its relation to TOC GTPases receptor proteins (Toc34 and Toc159), purified chloroplasts from pea were subjected to four different light conditions; dark (under dem red light), normal day light, low and high blue light intensities. Then, OEPs were subsequently extracted and subjected to in vitro protein phosphorylation assay. Phosphorylated OEPs were analyzed either by SDS-PAGE and COBB (Coomassie Brilliant Blue) staining or detected by immunoblotting against AntiPhosSer antibody (Fig. 1). To manifest the specificity of light dependent kinase activity on Toc34 (running approximately at $34 \mathrm{kDa}$ ) and Toc159 (running approximately at $159 \mathrm{kDa})$, signals obtained by Anti-PhosSer antibody were merged with the corresponding signals obtained by western blot using specific antibodies of G-domains of Toc34 and Toc159. Phosphorylation of PsToc34 and PsToc159 (truncated and/or full length) was confirmed as previously investigated (Sveshnikova et al., 2000; Fulgosi \& Soll, 2002; Jelic et al., 2002, 2003; Oreb et al., 2008 and Ibrahim, 2012). It was found that no difference in the phosphorylation profile and/or level of OEPs subjected to dark and normal light conditions (Fig. 1, lanes 1-2). Notably the phosphorylation level of OEPs were dramatically decreased under high light intensities (Fig. 1, lanes 6-8) campared to those treated with low light intensities (Fig. 1, lanes 3-5) as well as dark and normal light conditions. Phosphorylation of Toc34 was induced under low light and decreased significantly under high BL treatment compared to the dark and normal light conditions (Fig. 1, denoted by gray arrow). However, Toc159 was contrary to Toc34 in its phosphorylation, it was triggered at maximum peak under high BL intensity and was not detected under low light intensities (Fig. 1, denoted by blue arrow). Therefore, it was suggested that phosphorylation of OEPs, especially Toc34 and Toc159 is blue light dependent. Together, it might be concluded that phosphorylation of Toc34 is maintained conservatively in chloroplast, while in case of Toc159 is triggered under high light circumstances. High BL intensity is proposed 
to initiate chloroplast relocation movement, named avoidance movement of chloroplasts (Finn et al., 2010 and Lehmann et al., 2011). Several evidences have assessed the detection of Phot 2 at chloroplast outer envelope (Kong et al., 2012; Simm et al., 2013 and Aggarwal et al., 2014). Being more induced to be phosphorylated at high BL intensities, Toc159, but not Toc34, might be correlated with chloroplast avoidance movement by its interaction with blue light receptors Phot1 and/or Phot2.

Gene expression analysis of Toc core subunits and phototropins

To bring a comprehensive depiction about the expression of the TOC core complex and phototropins gene(s), their transcript levels were analyzed in $A$. thaliana L. leaves to gain insights into possible interaction, co-regulation and/or functions of these proteins. Firstly, gene chip analysis has shown the highest expression levels for AtToc75-III, AtToc33, and AtToc90 (Fig. 2A). High transcript levels of these proteins may give rise to a specific form of Toc core complex for translocation across the outer envelope under HL-triggered avoidance movement (Vojta et al., 2004). Interestingly, AtToc34, AtToc64-I, AtToc90, and AtToc132 were detected and shown an approximate similar expression, which was lower than the expression of AtToc75-III. Only AtToc120 was further drastically reduced. The data show differential gene expression of Toc33 and Toc159 isoforms in photosynthetically active tissue. These results may account for the reduction in the photosynthetic activities of AtToc33 knockout line (Oreb et al., 2007). These results were in line with the same findings of Vojta et al. (2004). Non-photosynthetic and photosynthetic proteins were suggested to use different Toc33 and Toc159 isoforms during their import into chloroplast (Kubis et al., 2004). Involvement of AtToc33 isoform in import of photosynthetic proteins (Kubis et al., 2004), and AtToc34 isoform for non-photosynthetic and housekeeping proteins (Jelic et al., 2003 and Agne \& Kessler, 2009) were reported. Discriminatory localization of Toc33 and Toc159 isoforms between tissues was evidenced (Kubis et al., 2004), where AtToc33, AtToc159 and AtToc90 more intended in leaves, while AtToc34, AtToc123, and $A t \operatorname{Toc} 120$ in roots. On the other hand, 26 phototropins and phototropin-like genes (Phot-Like) were expressed and indentified under HL applied conditions. Analysis of these genes has revealed significant high expression levels of Phot1 and Phot2 (Fig. 2B). Being concomitantly up regulated under HL intensity, Toc33 and Toc159 might be regulated by the kinase activity of Phot1 and/or Phot2. Secondly, validation of gene chip data was assured by construction of co-expression gene network In Silico using a plant co-expression database, ATTED-II ver.9.2 (Obayashi et al., 2018). It was found that expression of Toc33 and Toc159 transcripts were directly connected to each other on the network. Toc159 was found to indirectly connected to Phot2 by Reduced Chloroplast Coverage 1 and 2, REC1 (TAIR:AT1G01320) and REC2 (TAIR:AT4G28080), respectively (Fig. 3). REC1 and REC2 are protein-coding genes harboring TetratricoPeptide Repeats (TPR) domain with amidase activity. Latter two proteins contribute and work in ensemble with the third protein, REC3 to establish chloroplast size (Larkin et al., 2016). Under high light chloroplast avoidance movement is induced as one of plantdeveloped photoprotective mechanisms which include size re-adjustment of chloroplast and/or its subcompartment(s) (Givnish, 1988). That is typically has accounted for the direct connection of Phot 2 and REC1/REC2 upon unfavorable high light conditions. Therefore, a similar conclusion might be drawn that a kind of interaction and coregulation was evidenced between Phot $1 / 2$ and TOC GTPases based on gene chip analysis and constructed In Silico co-expression network.

Assessment protein-protein interaction between Phot 2 and TOC GTPases

Since Phot2 was identified at OEM of chloroplast and its expression was heavily detected in the phospho-mimicry mutant line (ppi1::S181A), therefore Co-IP protocol was performed to figure out the interacting partner(s) for Phot2 at OEM of chloroplast. To reveal interactions between functional proteins at physiological relevant and to get closer to the thought after interacting partners AtPHOT2-KD antibody was immobilized on Protein-A- Sepharose beads. The results have shown that the interaction of Phot 2 is confirmed with Toc159 and Toc75 (Fig. 4), but not with Toc33. It has been noticed that the interaction is higher with Toc75 at second and third elution fractions (Fig. 4, lanes 7 and 8, respectively), but with only the third elution in case of Toc159 (Fig. 4 lane 8). Weak interaction between AtPHOT2$\mathrm{KD}$ and G-domain of Toc159 was attributed to fast, instantaneous and transient interaction during the phosphorylation process between the protein kinase and its proposed target protein (Phot2 and Toc159, respectively). 


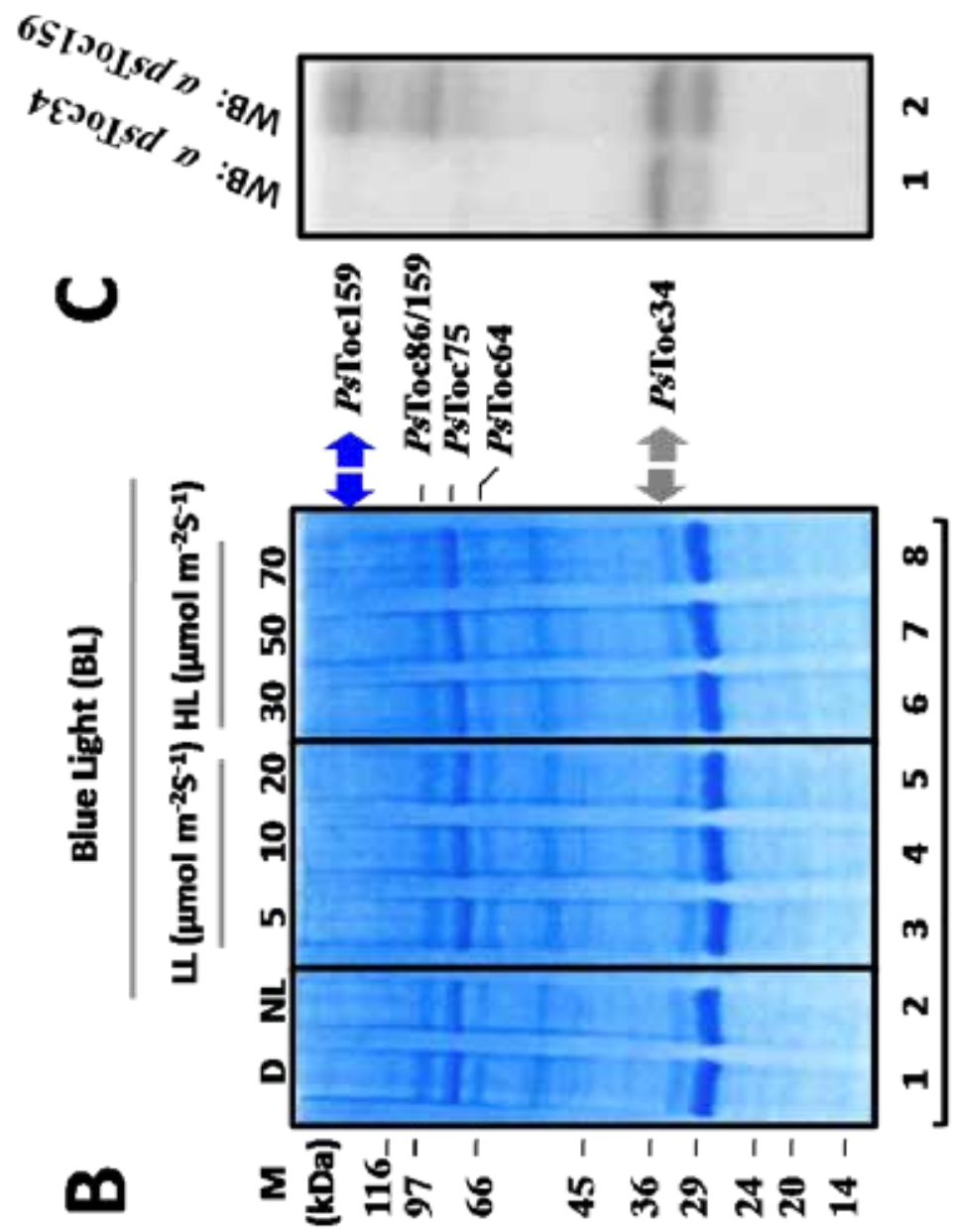

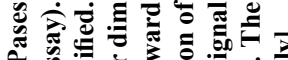

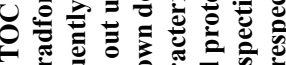

숭

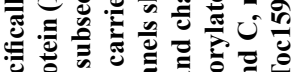

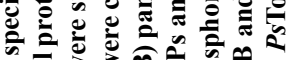

की

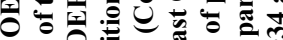

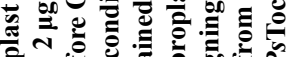

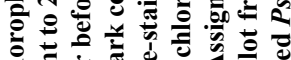

흘

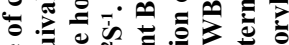

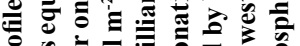

产客

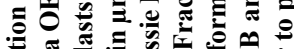

का

อ.

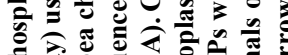

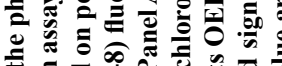

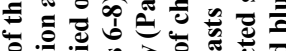

so

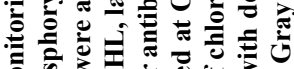

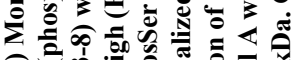

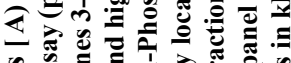

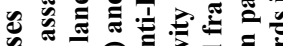

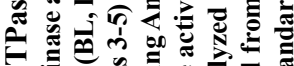

O

ช

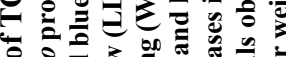

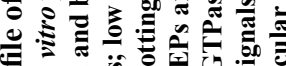

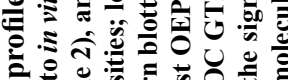

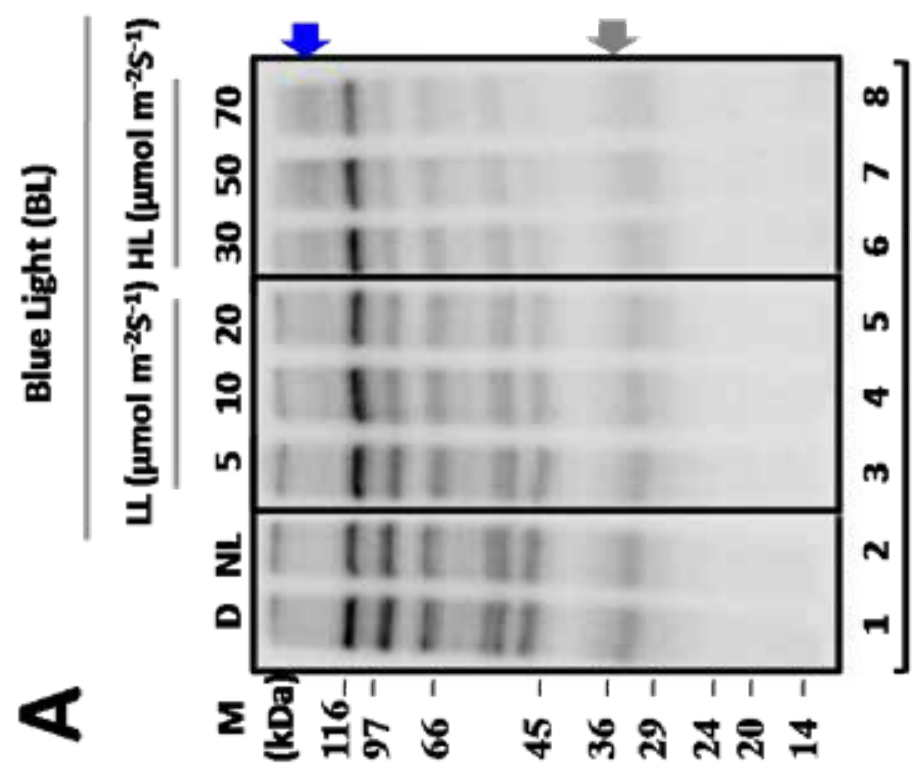

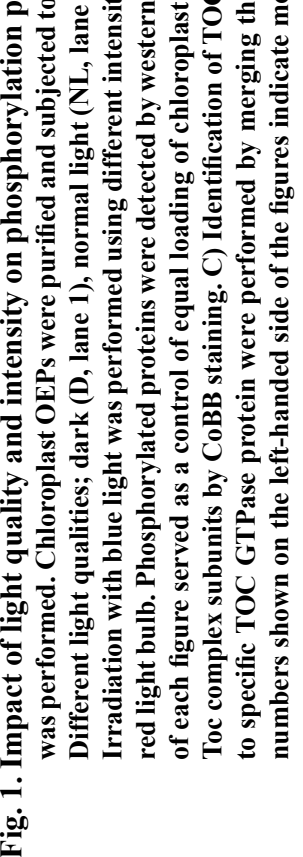




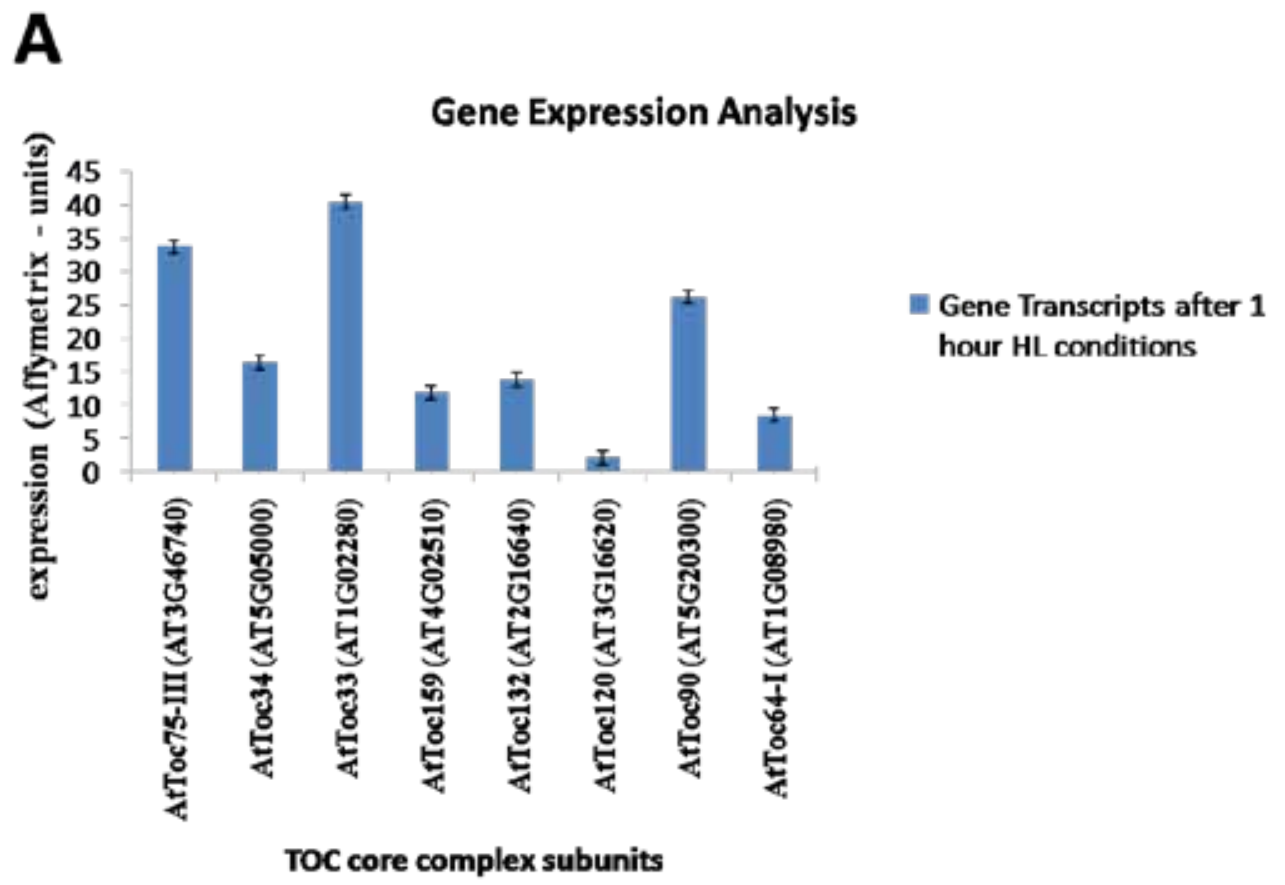

B

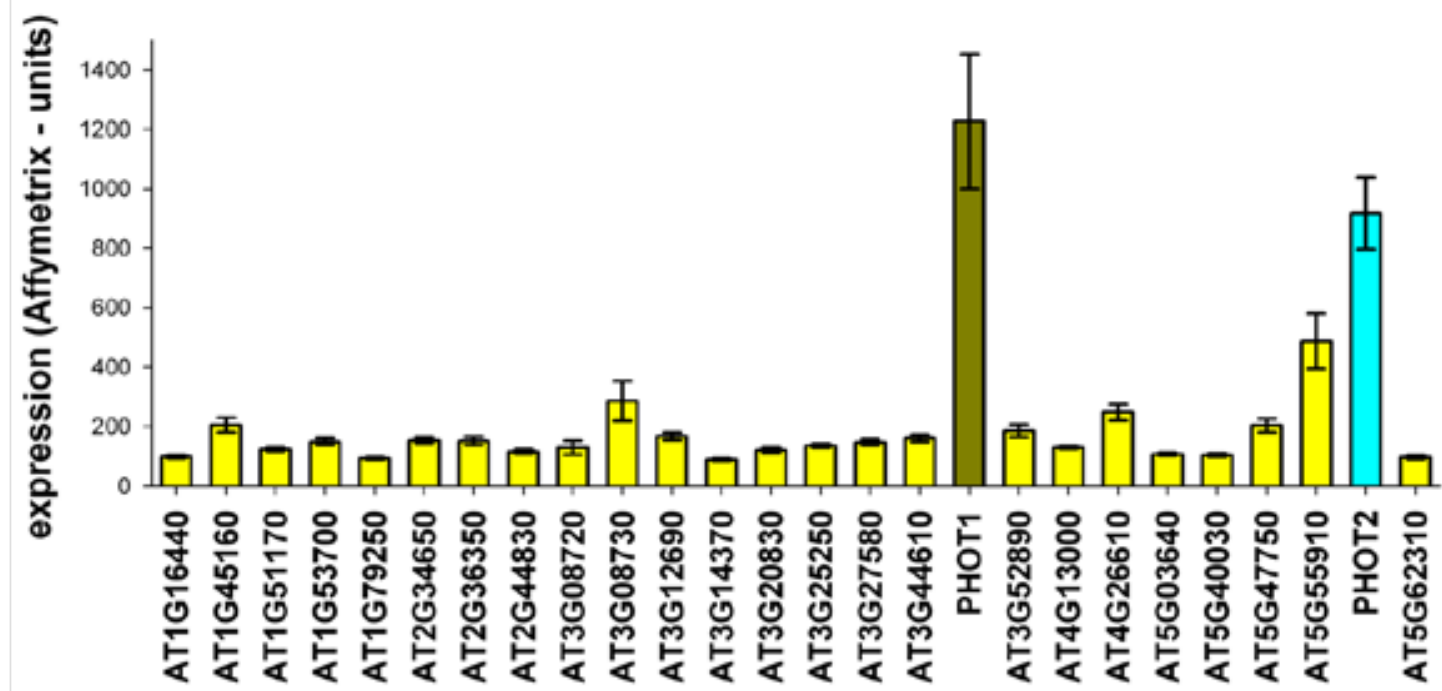

Fig. 2. Gene chip analysis of Toc core subunits and phototropins [Expression levels of the TOC complex subunits (panel A) and phototropins/phototropin-like genes (panel B) in A. thaliana leaves were analyzed by Affymetrix expression analysis. $Y$ axis values refer to normalized gene chip scores (signals) shown as expression units of three independent biological replicates. The expression values of investigated transcript levels were normalized according to the highest observed expression].

Two evidences have supported the notion of Phot 2 and Toc159 interaction; Firstly, serine/ threonine protein kinase is responsible for Toc159 phosphorylation (Fulgosi \& Soll, 2002) which is the same protein kinase family of Phot2. Secondly, Toc159 is phosphorylated in cytosolic-localized
G-domain (Fulgosi \& Soll, 2002; Jelic et al., 2003; Oreb et al., 2008). On the other hand, investigated results are in harmony with the co-expressed gene network mentioned above regarding possible interaction and/or co-regulation between Phot2 and TOC GTPases, specifically Toc159 (Fig. 3). 


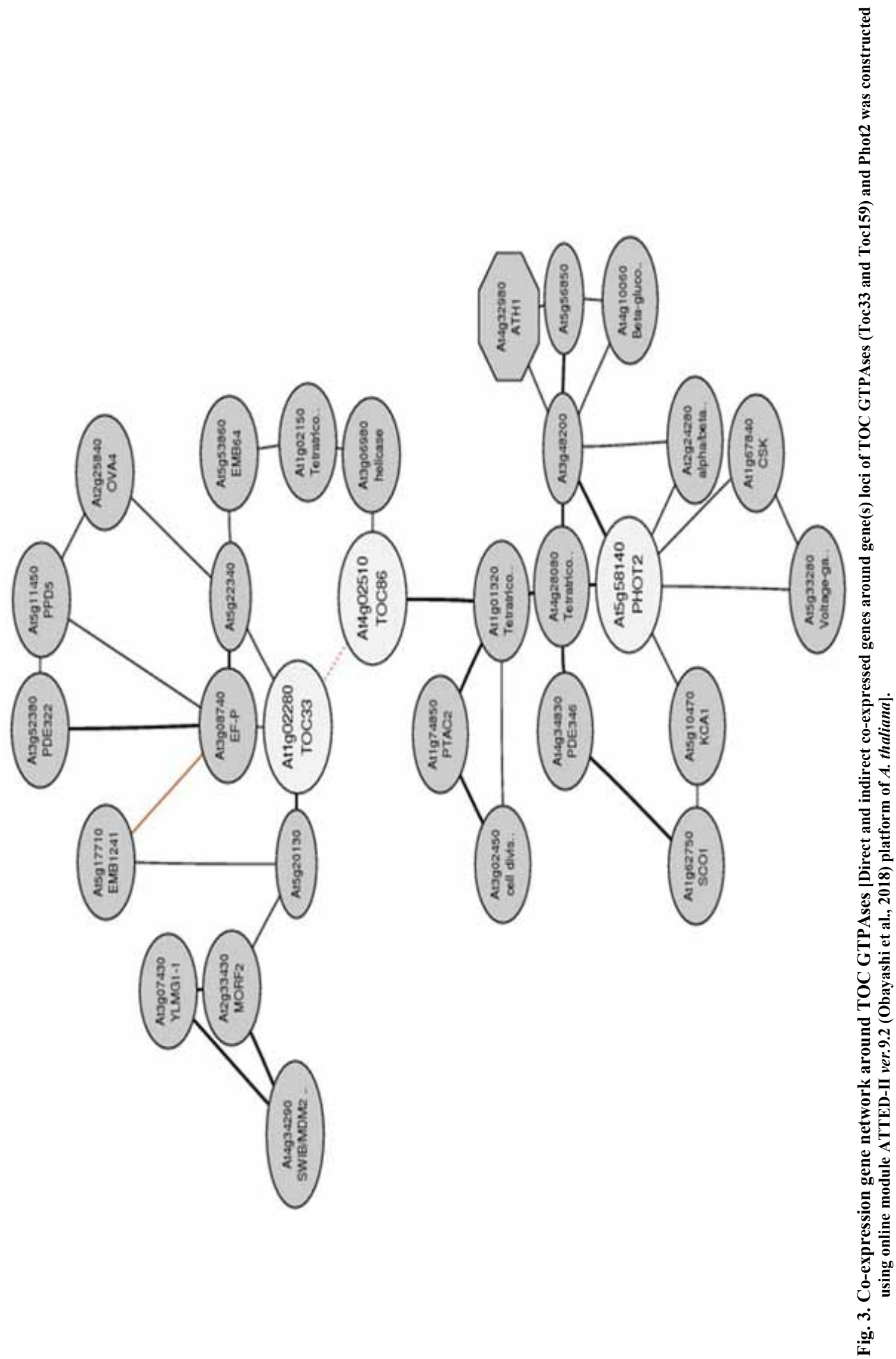

Egypt. J. Bot. 59, No.1 (2019) 


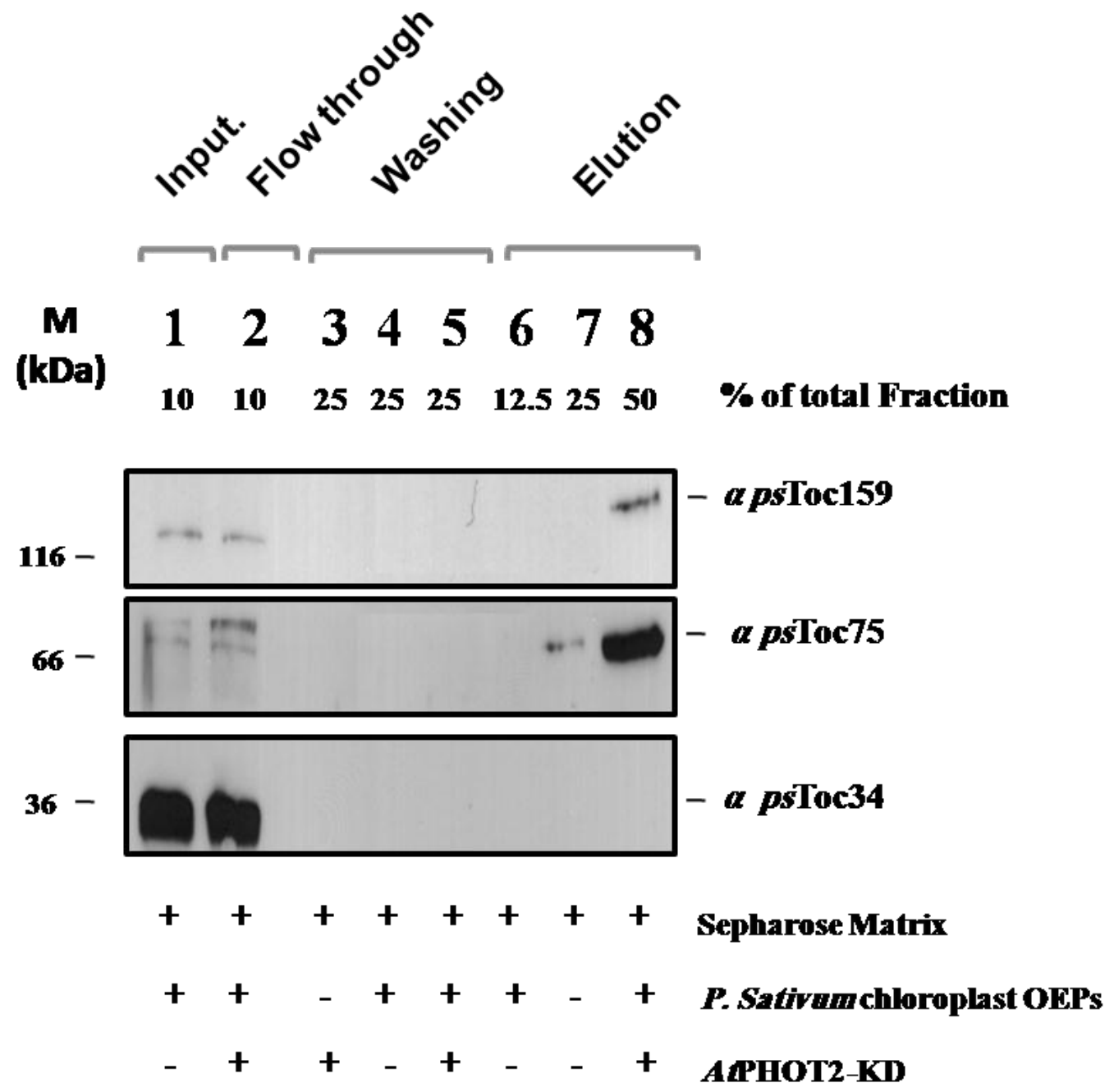

Fig. 4. Confirmation the interaction between Phot2 and TOC GTPases by Co-IP [Co-IP protocol against $\alpha$-AtPHOT2KD antibody was performed. Outer envelope membranes of chloroplasts (equivalent to $70 \mu \mathrm{g}$ total protein content) were solubilized by $1.5 \%(\mathrm{w} / \mathrm{v})$ digitonin (Input, lane 1). Solubilized membrane proteins were passed over Sepharose matrix immobilized with $\alpha$-AtPHOT2-KD antibody. Unbound membrane proteins fraction (Flow through, lane 2) was collected. The Sepharose matrix was then washed by Co-IP-buffer included $25 \mathrm{mM} \mathrm{HEPES/KOH,} \mathrm{pH} 7.6,150 \mathrm{mM} \mathrm{NaCl}$ for three times (Washing, lanes 3-5). Interacting proteins were eluted from Sepharose matrix (Elution, lanes 6-8)].

Specificity of Phot2 kinase activity towards Toc34 and Toc159

To manifest the specificity of Phot2 kinase activity towards TOC GTPases, in vitro protein phosphorylation assay was performed using knockout line ( $\triangle A t \mathrm{Phot} 2)$ and wild type $A$. thaliana plants (WT). Furthermore, it was reported that Phot1 blue light receptor functions in high light fluence rates to regulate and/or mediate phototropic responses with Phot2 (Zhao et al., 2013). Hereby, using knockout line of $A$. thaliana phototropin1 ( $\triangle A t$ Phot1) was taken into consideration and in execution of in vitro protein phosphorylation assay. Intact chloroplasts purified from WT, $\triangle A t$ Phot2, $\triangle A t$ Photl genotypes were subjected to in vitro kinase assay to assess presence/absence of TOC GTPases phosphorylation, especially Toc159. It was found that AtToc33 and AtToc86, proteolytic and truncated fragment of Toc159 (Hirsch et al., 1994; Kubis et al., 2004 and Agne \& Kessler, 2009), were phosphorylated in all studied genetic background (Fig. 5). These findings lead to the conclusion that Phot 1 and Phot2 are not the specific protein kinases responsible for phosphorylation of TOC GTPases. On the same context, triggered phosphorylation of Toc33 and Toc86/159 in $\triangle A t$ Phot 2 and $\triangle A t$ Phot 1 refers to presence of another signal transduction cascades might be connected with the other identified and expressed 24 PHOT-LIKE gene transcripts (Fig. 2B). To 
address the validity of this speculation, structural and functional analyses discussing the nature and localization of pre-mentioned PHOT-LIKE genes should be further investigated. Moreover, T-DNA insertion lines might be conducted by reverse genetics to monitor and survey the kinase activity and specificity of expressed PHOT-LIKE proteins towards TOC GTPases.

\section{Conclusion}

Taken all together, it is most likely concluded that interaction of Phot 2 with TOC GTPases, specifically Toc159, is related to photo-induced chloroplast movement and relocation, but not with regulation of protein import into chloroplast by phosphorylation of TOC translocon receptor proteins, Toc33 and Toc159. The identification of the regulatory units and characterization of the influence of receptor phosphorylation on plastid and plant development signs important for the integration of the translocation into the regulatory network of the cell need to be more focused and studied. Thereby, signs essential to understand the plastid-cell communication. The outcome will place the protein translocation into chloroplast into a broader picture of signal perception and transduction of plants at cellular level.

Acknowledgments: The authors are so grateful to Prof. Dr. Enrico Schleiff and Prof. Dr. John Cristie for their keen support and Kind providing of so valuable materials and reagents without which this work would not have appeared to light. The authors greatly appreciate Prof. Dr. Schleiff for his knowledge valorization and sharing his state of art dataset of gene chip analysis of Phot-like genes to enrich present study. Thanks are also extended to Prof. Dr. Maher M. Shehata for his sincere comments and advices during preparation of the initial draft of this manuscript.

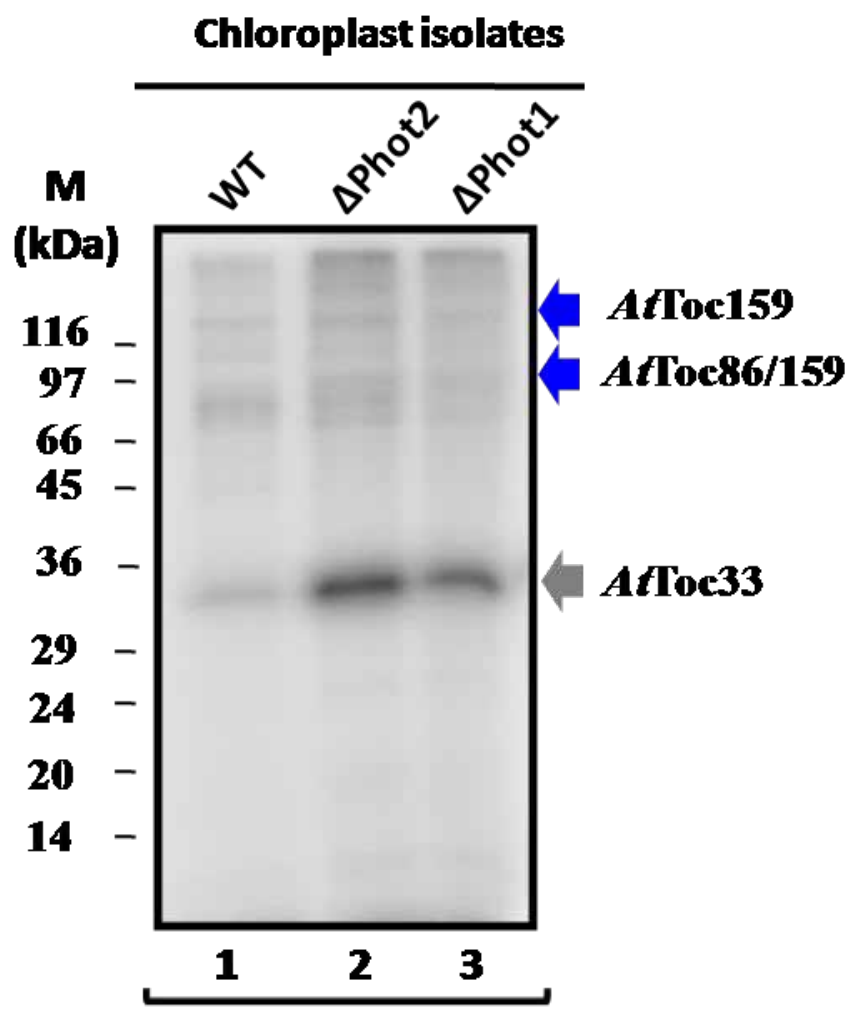

WB: Anti-PhosSer

Fig. 5. Specificity of Phot2/Phot1 kinase activity towards TOC GTPases [Intact chloroplasts were identified from WT, $\Delta$ Phot2, and $\triangle$ Phot1 genetic backgrounds. Initial analysis of Phot2 and Phot1 kinase activity in wild type (WT, lanes 1-3), $\Delta$ Phot2 (lanes 4-6), and $\triangle$ Phot1 (lanes 7-9) towards TOC GTPases was shown. The numbers shown on the lefthanded side of the figures indicate molecular weight standards in kDa. Gray and blue arrows refer to phosphorylated ATToc33 and AtToc86/159, respectively. Phosphorylated proteins were detected by western blotting (WB) using AntiPhosSer antibody]. 


\section{References}

Aggarwal, C., Banaś, A.K., Kasprowicz-Maluśki, A., Borghetti, C., Łabuz, J., Dobrucki, J. and Gabryś, H. (2014) Blue-light-activated phototropin2 trafficking from the cytoplasm to Golgi/post-Golgi vesicles. Journal of Experimental Botany, 65(12), 3263-3276. Doi:10.1093/jxb/eru172.

Agne, B. and Kessler, F. (2009) Protein transport in organelles: The Toc complex way of preprotein import. FEBS J. 276, 1156-65.

Becker, T., Jelic, M., Vojta, A., Radunz, A., Soll, J. and Schleiff, E. (2004) Preprotein recognition by the TOC complex. EMBO J. 23, 520-530.

Christie, J.M. (2007) Phototropin blue-light receptors. Annu. Rev. Plant Biol. 58, 21-45.

Christie, J.M., Reymond, P., Powell, G.K., Bernasconi, P., Raibekas, A.A., Liscum, E. and Briggs, W.R. (1998) Arabidopsis NPH1: A flavoprotein with the properties of a photoreceptor for phototropism. Science, 282, 1698-1701.

Christie, J.M., Salomon, M., Nozue, K., Wada, M. and Briggs, W.R. (1999) LOV (light, oxygen, or voltage) domains of the blue-light photoreceptor phototropin (nph1): Binding sites for the chromophore flavin mononucleotide. Proc. Natl. Acad. Sci. 96, 8779-8783.

Christie, J.M., Gawthorne, J., Young, G., Fraser, N.J. and Roe, A.J. (2012) LOV to BLUF: Flavoprotein contributions to the optogenetic toolkit. Mol. Plant, $5,533-544$.

Finn, R.D., Mistry J., Tate, J., Coggill, P., Pollington, J.E., Gavin, O.L., Gunasekaran, P., Cenic, G., Forsland, K., Holm, L., Sonnhammer, E.L., Eddy, S.R. and Bateman, A. (2010) The pfam protein families database. Nucleic Acids Res. 38, D211-22.

Franklin, K.A. and Quail, P.H. (2010) Phytochrome functions in Arabidopsis development. J. Exp. Bot. 61, 11-24.

Fulgosi, H. and Soll, J. (2002) The chloroplast protein import receptors Toc34 and Toc159 are phosphorylated by distinct protein kinases. J. Biol. Chem. 277, 8934-40.

Givnish, T.J. (1988) Adaptation to sun and shade: A whole plant perspective. Autralian Journal of Plant Physiology, 15, 36-92.

Hinnah, S.C., Wagner R., Svenshikova, N., Harrer, R. and Soll, J. (2002) The chloroplast protein import channel Toc75: Pore properties and interaction with transit peptides. Biophys J. 83, 899-911.

Hirsch, S., Muckel, E., Heemeyer, F., von Heijne, G. and Soll, J. (1994) A receptor component of the chloroplast protein translocation machinery. Science, 266, 1989-1992.

Ibrahim, M. (2012) First insights into the phosphorylation of Toc34 proteins. Ph.D. Thesis, Department of Molecular Biosciences, Goethe University, Frankfurt am Main, Germany, p. 106.

Jarvis, P. (2008) Targeting of nucleus-encoding proteins to chloroplasts in plants. New Phytol. 179, 257-285.

Jelic, M., Sveschnikova, N., Motzkus, M., Hörth, P., Soll, J. and Schleiff, E. (2002) The chloroplast import receptor Toc34 functions as preproteinregulated GTPase. Biol. Chem. 383, 1875-83.

Jelic, M., Soll, J. and Schleiff, E. (2003) Two Toc34 homologues with different properties. Biochemistry, 42, 5906-16.

Kausch, K.D. and Handa, A.K. (1997) Molecular cloning of a ripening specific lipoxygenase and its expression during wild-type and mutant tomato fruit development. Plant Physiol. 113, 1041-1050.

Kennis, J.T., Crosson, S., Gauden, M., van Stokkum, I. H., Moffat, K. and van Grondelle, R. (2003) Primary reactions of the LOV2 domain of phototropin, a plant blue-light photoreceptor. Biochemistry, 42, 3385-3392.

Kessler, F., Blobel, G., Patel, H.A. and Schnell, D.J. (1994) Identification of two GTP-binding proteins in the chloroplast protein import machinery. Science, 266, 1035-9.

Kong, S.G., Suetsugu, N., Kikuchi, S., Nakai, M., Nagatani, A. and Wada, M. (2012) Both phototropin 1 and 2 localize on the chloroplast outer membrane with distinct localization activity. Plant and Cell Physiology, 54(1), 80-92. https://doi.org/10.1093/ pcp/pcs 151 .

Kubis, S., Patel, R., Combe, J., Bédard, J., Kovacheva, 
S., Lilley, K., Biehl, A., Leister, D., Ríos, G. and Koncz, C., et al (2004) Functional specialization amongst the Arabidopsis Toc159 family of chloroplast protein import receptors. Plant Cell, 16, 2059-2077.

Laemmli, U.K. (1970) Cleavage of structural proteins during the assembly of the head of bacteriophage T4. Nature, 227, 680-685.

Larkin, R.M., Stefano, G., Ruckle, M.E., Stavoe, A.K., Sinkler, C.A., Brandizzi, F., Malmstrom, C.M. and Osteryoung, K.W. (2016) Reduced chloroplast coverage genes from Arabidopsis thaliana help to establish the size of the chloroplast compartment. Proc. Natl. Acad. Sci. 113(8), 1116-25. Doi: 10.1073/pnas.1515741113.

Lehmann, P., Bohnsack, M.T. and Schleiff, E. (2011) The functional domains of the chloroplast unusual positioning protein1. Plant Sci. 180, 650-654.

Li, H.M., Kesavuli, M.M., Su, P.H., Yeh, Y.H. and Hsiao, C.D. (2007) Toc GTPase. J. Biomed. Sci. 14, 505-8.

Liu, H., Liu, B., Zhao, C., Pepper, M. and Lin, C. (2011) The action mechanisms of plant cryptochromes. Trends Plant Sci. 16, 684-691.

Martin, T., Sharma, R., Sippel, C., Waegemann, K., Soll, J. and Vothknecht, C.U. (2006) A protein kinase family in Arabidopsis phosphorylates chloroplast precursor proteins. J. Biol. Chem. 281, 40216-40223.

Möglich, A., Yang, X., Ayers, R.A. and Moffat, K. (2010) Structure and function of plant photoreceptors. Annu. Rev. Plant Biol. 61, 21-47.

Obayashi, T., Aoki, Y., Tadaka, S., Kagaya, Y. and Kinoshita, K. (2018) ATTED-II in (2018) A plant coexpression database based on investigation of the statistical property of the mutual rank index. Plant Cell Physiol. 59(1), e3. Doi: 10.1093/pcp/pcx191.

Oreb, M., Zoryan, M., Vojta, A., Maier, U.G., Eichacker, L.A. and Schleiff, E. (2007) Phospho-mimicry mutant of atToc33 affects early development of Arabidopsis thaliana. FEBS Lett. 581,5945-51.

Oreb, M., Höfle, A., Mirus, O. and Schleiff, E. (2008) Phosphorylation regulates the assembly of chloroplast import machinery. J. Exp. Bot. 59(9), 2309-2316.
Qbadou, S., Becker, T., Mirus, O., Tews, I., Soll, J. and Schleiff, E. (2006) The molecular chaperone Hsp90 delivers precursor proteins to the chloroplast import receptor Toc64. EMBO J. 25, 1836-1847.

Sakai, T., Kagawa, T., Kasahara, M., Swartz, T. E., Christie, J.M., Briggs, W.R., Wada, M. and Okada, K. (2001) Arabidopsis nph1 and npl1. Blue light receptors that mediate both phototropism and chloroplast relocation. Proc. Natl. Acad. Sci. 98, 6969-6974.

Salah, A., Khalifa, N.S., Shehata, M.M., Abdelsattar, M.T. and Ibrahim, M. (2016) Deciphering the effects of temperature stress on RuBisCO large subunit and its complex assembly. Egypt. J. Exp. Biol. (Bot.), 12(1), 9-19.

Sambrook, J.E., Fritsch, F. and Maniatis, T. (1989) "Molecular Cloning - A Laboratory Manual". $2^{\text {nd }}$ ed. Cold Spring Harbor Laboratory Press, New York.

Schleiff, E., Soll, J., Küchler, M., Kühlbrandt, W. and Harrer, R.. (2003) Characterization of the translocon of the outer envelope of chloroplasts. $J$. Cell Biol. 160, 541-51.

Schleiff, E., Soll, J., Sveshnikova, N., Tien, R., Wright, S., Dabney-Smith, C., Subramanian, C. and Bruce, B.D. (2002) Structural and guanosine triphosphate/diphosphate requirements for transit peptide recognition by the cytosolic domain of the chloroplast outer envelope receptor, Toc34. Biochemistry, 41, 1934-46.

Schnell, D.J., Blobel, G., Keegstra, K., Kessler, F., Ko, K. and Soll, J. (1997) A nomenclature for the protein import components of the chloroplast envelope. Trends Cell Biol. 7, 303-4.

Simm, S., Papasotiriou, D.G., Ibrahim, M., Leisegang, M.S., Müller, B., Schorge, T. and Schleiff, E. (2013) Defining the core proteome of the chloroplast envelope membranes. Frontiers in Plant Science, 4, 11. http://doi.org/10.3389/fpls.2013.00011

Soll, J. and Schleiff, E. (2004) Protein import into chloroplasts. Nat. Rev. Mol. Cell Biol. 5, 198-208.

Sveshnikova, N. (2000) Characterization of two components of the translocation complex of chloroplast outer envelopes. Disseration, ChristianAlbrechts-Universität Kiel. Germany. 
Swartz, T.E., Corchnoy, S.B., Christie, J.M., Lewis, J.W., Szundi, I., Briggs, W.R. and Bogomolni, R.A. (2001) Thephotocycle of a flavin-binding domain of the blue light photoreceptor phototropin. J. Biol. Chem. 276, 36493-36500.

Vojta, A., Alavi, M., Becker, T., Küchler, M., Hörmann, F., Soll, J., Thomson, R. and Schleiff, E. (2004) The protein translocon of the plastid envelopes. $J$. Biol. Chem. 279, 21401-21405.

Waegemann, K. and Soll, J. (1996) Phosphorylation of the transit sequence of chloroplast precursor proteins. J. Biol. Chem. 271, 6545-6554.

Zhao, X., Wang, Y.L., Qiao, X.R., Wang, J., Wang, L.D., Xu, C.S. and Zhang, X. (2013) Phototropins function in high-intensity blue light-induced hypocotyl phototropism in Arabidopsis by altering cytosolic calcium. Plant Physiology, 162, 15391551. DOI: 10.1104/pp.113.216556.

(Received 29/10/2018; accepted 4/12/2018)

\section{التفاعل الايناميكي بين بروتين Toc159 ومستقبلات الضوء الأزرق على الغلاف الخارجي \\ للابلاستيدات الخضراء \\ هبة حمدى و محمد إبراهيم \\ قسم النبات ـ كلية العلوم - جامعة عين شمس مس - القاهرة - مصر.}

لقد قرنت الأهمية الفسيولوجية لعملية فسفرة البروتين Toc33 (وحدة بروتينية ذات وزن جزيئى 33 كبلو دالتون

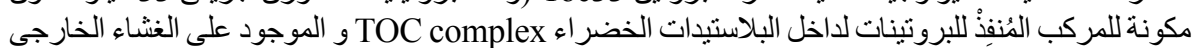

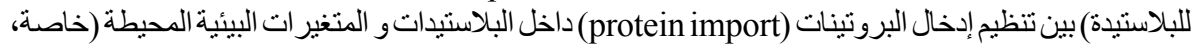

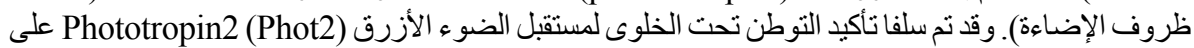

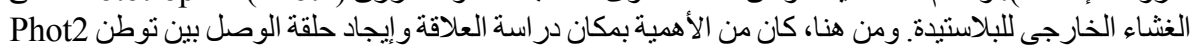

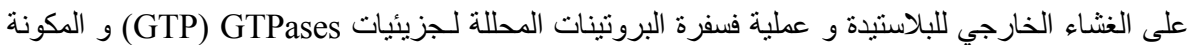

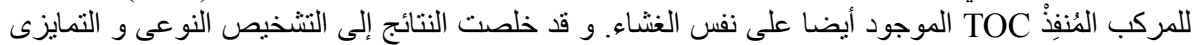

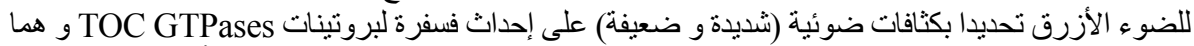

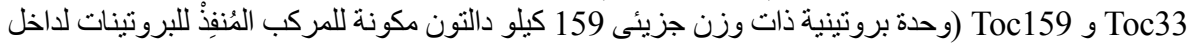

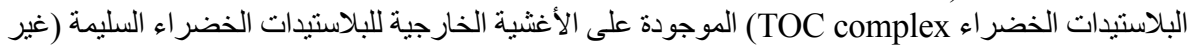

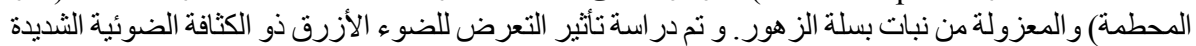

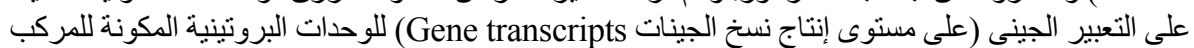

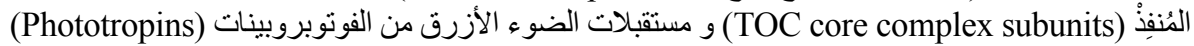

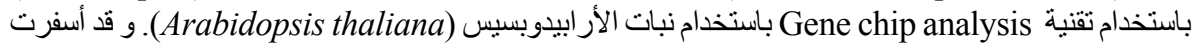

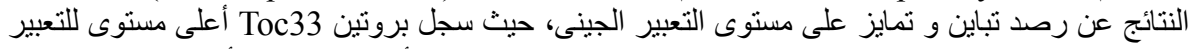

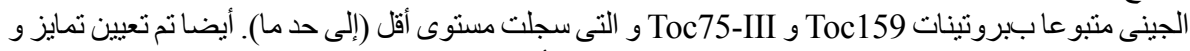

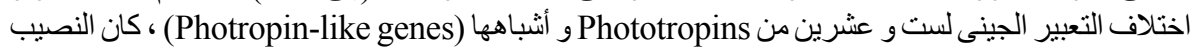

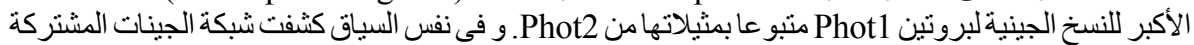
للتعبير الجيني (Co-expression gene netweork) ل

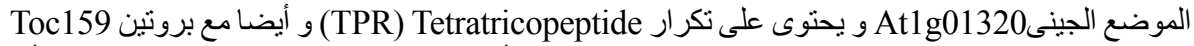

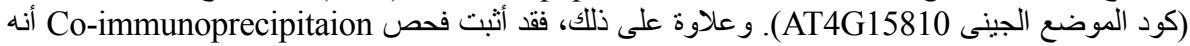

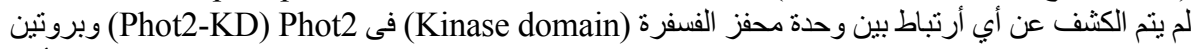

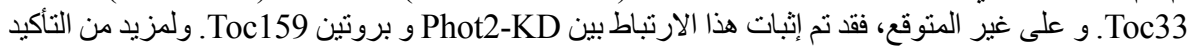

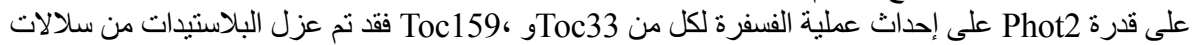

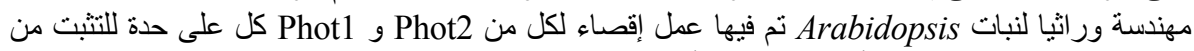
استمر ار إحداث عملية الفسفرة أو غيابها. و لقد أظهرت النتائج استمر ار فسفرة

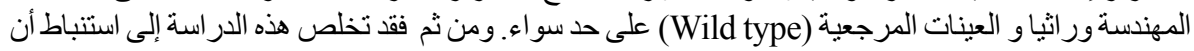

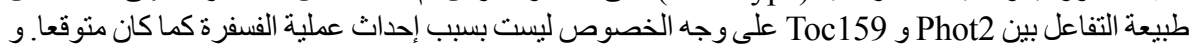

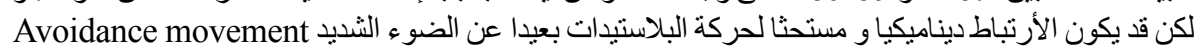

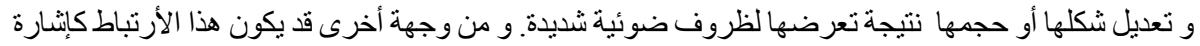
حث ترتبط بعملية نشأة البلاستيدات chloroplast biogenesis. و و تفتح هذه الإر اسة آفاقا جديدة لفهم و استنباط،

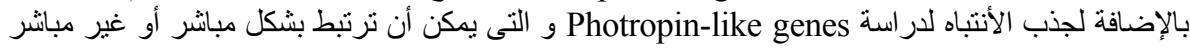

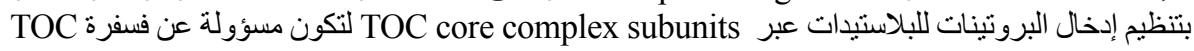

. GTPase 